\title{
Álvaro de Luna: A construção política da imagem do valido (Castela, século XV)
}

\section{Cássio Lopes Aquino*}

DOI: 10.11606/issn.2318-8855.v10i2p648-669

Resumo: Este artigo deseja apresentar como a imagem de um personagem muito importante da história castelhana, Álvaro de Luna, foi construída a partir de uma visão específica, principalmente, de determinadas crônicas e da historiografia sobre a nobreza cortesã. Através de um estudo qualitativo de fontes do período, sobretudo das crônicas, é interessante perceber suas intenções e sentidos políticos, permitindonos conhecer lógicas de representação do poder. A imagem construída de Álvaro de Luna decorre de um conteúdo político a partir da literatura que se amalgama a um jogo intenso de poder durante o reinado de Juan II, na Castela do século XV. Ao desafiar grupos importantes da corte e assumir gradativamente poderes e funções como a de Condestable e de Gran Maestre de la Orden de Santiago - o valido ameaçou a posição de parte da nobreza e seus privilégios. Assim, a versão negativa, por parte das crônicas, reflete em boa medida a opinião da corte régia sobre Álvaro de Luna, por ser o local de produção dessas fontes. A pesquisa procura entender o contexto político castelhano que envolve o personagem para refletir sobre os motivos de tal construção, dialogando, igualmente, com uma historiografia tradicional que coloca a figura do valido, de maneira geral, como usurpador do caráter monocrático do poder régio. A análise apoia-se numa perspectiva pluralista do poder, característica do período medieval, que estrutura a monarquia e a fortalece como parte desse sistema.

Palavras-chaves: Álvaro de Luna; Castela Medieval; Pluralismo Político; Valimiento.

* Graduando em História pela Universidade de Brasília (UnB); colaborador do Programa de Estudos Medievais (PEM-UnB). E-mail: cassiolopesaquino@gmail.com 


\section{O Poder na Idade Média}

\section{Álvaro de Luna: A construção política da imagem do valido}

\section{I. Álvaro de Luna na corte de Juan II e o conceito de valimiento}

O conceito de valido e o seu papel na história tem um dos seus principais capítulos na Castela, do século XV. Os validos são apresentados, nas fontes, com os nomes de "favorito" e/ou "privado", e eram cargos "não oficiais"1 cuja ascensão dentro da corte e a atribuição de funções eram decorrentes da própria confiança e vontade do rei. A íntima amizade com o rei e a intervenção consentida e direta no governo da monarquia são outras características que representam o valimiento (TOMÁS Y VALIENTE, 1982, p. 32). O reinado de Juan II (1406 - 1454) possuiu um dos principais validos da história de Castela e um dos mais controversos para o cenário político: Álvaro de Luna. O "favorito" possuiu uma trajetória particular de ascensão e queda, que auxilia, de uma maneira bastante efetiva, a entender o contexto político que envolvia tal personagem e os desdobramentos políticos que marcaram a primeira metade do século XV, em Castela.

O "privado" foi introduzido na corte de Castela através de seu tio, Pedro de Luna, então arcebispo de Toledo. Logo, segundo a Crónica de Juan II, ele se tornou o principal "privado" do rei e assumiu cargos e funções bastante proeminentes ao longo desse reinado. Apesar da importância que o valido teve para as campanhas militares e políticas durante seu tempo de atuação na corte, ele acabou por ser decapitado, em 1453, a mando do próprio monarca:

Pues los que con tanto estudio trabajáis por haber estados, riquezas, dignidades, mirad que no vio toda la gloria, todo el tesoro, todo el mando, todo el poder deste Maestre é Condestable : el qual después de haber regido y gober-

\footnotetext{
${ }^{1}$ Este conceito, embora problemático, é amplamente usado pela historiografia. Entender o conceito de valimiento como um poder "não oficial" é bastante representativo da caracterização política anacrônica que o termo carrega. A oficialidade ou a falta de oficialidade do cargo de valido depende quase exclusivamente da perspectiva de quem o adota.
} 


\section{O Poder na Idade Média}

Cássio Lopes Aquino

nado á su libre voluntad por espacio de treinta años y más los Reynos de Castilla y de León, y haber habido tan grandes con tan altas dignidades, se vido solo, desanparado de sus amigos e criados, e ageno de todos los bienes que la fortuna le dio, preso, encarcelado, pobre, se oyó por justicia pregonar, y degollar en un cadahalso en la plaza de Valladolid, habiéndole de dar por amor de Dios para su sepultura (PÉREZ DE GUZMÁN, 1779, p. 575).

De fato, a ascensão de alguém que não fora criado e oriundo da nobreza cortesã incomodou grupos de nobres que já se encontravam enraizados na corte. O conteúdo das crônicas do período, produzidas na própria corte, retratam Álvaro de Luna sob vários pontos de vista, essencialmente políticos. Neste artigo, irei ater-me a duas que reproduzem versões opostas sobre a atuação do valido: a Crónica del Halconero de Juan Il e a Crónica de don Álvaro de Luna. A primeira retrata o valido de uma forma bastante negativa, chegando a insinuar, inclusive, um vínculo íntimo entre ele e o rei, e acusando Álvaro de Luna de realizar encantamentos mágicos para submeter o monarca a seus desejos. A segunda o retrata como o arquétipo do ideal cavaleiresco e sujeito de boa conduta, selecionando episódios, se debruçando sobre os favoráveis e omitindo os desfavoráveis. As diferentes opiniões que as crônicas apresentam permitem conhecer a diversidade de polos de poder que se apoiam em uma literatura política para construir a sua versão sobre determinados acontecimentos. Os conteúdos dessas fontes e suas diferentes características auxiliam a perceber a trajetória do condestable a partir de filtros distintos que constituem os principais pontos de vista e produzem narrativas contrastantes.

Então, é importante analisar a construção política dessa literatura e como ela contribuiu para a estruturação da imagem de Álvaro de Luna, assim como a historiografia tradicional que acusa os validos de perturbarem fortemente o cenário político, numa época em que a monarquia estaria em processo de fortalecimento. Portanto, esses personagens atrapalhariam a eficácia política dos reis. 


\section{O Poder na Idade Média}

\section{Álvaro de Luna: A construção política da imagem do valido}

O próprio conceito do valimiento e/ou privanza, com uma forte carga da herança historiográfica moderna, está na base do entendimento da imagem atribuída a Álvaro de Luna, que frequentemente assume o discurso das crônicas. O emprego do termo privanza, semanticamente, como sinônimo de valimiento, e sua semelhança de sentido com as palavras "privado" e "privatização" são exemplos dessa elaboração. 0 sentido atribuído a tal termo permitiu à historiografia construir um entendimento anacrônico de que, naturalmente, o valido estaria privatizando o poder público (monárquico), deslocando outros grupos para exercer o poder de forma monopolista e favorecer seus interesses particulares. A maneira de apresentar o exercício do poder do valido como um exercício "privado" gera uma dicotomia com o ideal de poder público, que não é próprio da Idade Média. Esse molde dicotômico de pensamento não permite compreender a complexidade da dimensão pública do período, com contornos jurídicos e políticos de tipo pluralista ${ }^{2}$.

Observa-se, igualmente, que parte da historiografia costuma associar o fenômeno da privança à debilidade política da própria monarquia, como se pode depreender da interpretação de Julio Valdeón, sobre as intenções do valido na corte de Juan II:

O que pretendia dom Álvaro de Luna? Sem dúvida, a ambição pessoal contava muito. Aquele que seria o novo condestável se aproveitou da debilidade do monarca para centralizar o poder ao redor de sua pessoa. (VALDÉON BARUQUE, 1968, p. 122- 123. Tradução nossa).

É nítido o peso que o autor coloca em como o valido se aproveitava da suposta fraqueza do monarca para concentrar o poder em torno de sua pessoa, constatando

\footnotetext{
${ }^{2}$ Esta maneira de compreender o exercício de poder no período medieval será mais bem explorada no segundo ponto deste artigo.
} 


\section{O Poder na Idade Média}

Cássio Lopes Aquino

a forte ambição pessoal de Álvaro de Luna ao colocar seus desejos acima das vontades régias.

María del Pilar Carceller Cerviño, por seu lado, apresenta assim o fenômeno:

Uma das principais características da privanza era sem dúvida alguma a adoção por parte do privado das funções do rei. Ele atuava como governante no lugar do monarca, sendo assim capaz de controlar o reino e as engrenagens do poder. (CARCELLER CERVIÑO, 2009, p. 88. Tradução nossa).

Portanto, entre esses autores e outros que abordam o tema prevalece uma interpretação que Francisco Tomás y Valiente denomina como "psicologista", associando o fenômeno do valimiento a uma simples relação de causa e efeito. Logo, a existência dos validos explica-se porque os reis foram pouco afeitos ao seu ofício - "preguiçosos" - ou porque eram doentes (TOMÁS Y VALIENTE, 1982, p. 34).

Essa abordagem por parte da historiografia converte a privança de Álvaro de Luna e a sua atuação política em mera prefiguração da interpretação "psicologista" sobre os validos (FORONDA, 2006, p. 73). Tal maneira de considerar o tema não auxilia na compreensão do papel político de Álvaro de Luna no complexo marco institucional da monarquia medieval, por esconder a dinamicidade do exercício de poder nesse período, bem como suas características de pluralismo político. A interpretação "psicologista" por parte da historiografia sobre o papel dos validos influencia na idealização a posteriori da imagem de Álvaro de Luna: um usurpador do poder, que impediu o rei de exercer corretamente seu papel de cabeça política.

\section{O valido como usurpador do caráter monocrático do poder régio?}

A historiografia, de cunho tradicional, tende a abordar os validos como agentes que impossibilitavam o estabelecimento de um poder centralizado, ou seja, de um 


\section{O Poder na Idade Média}

Álvaro de Luna: A construção política da imagem do valido

Estado com características modernas. A perspectiva anacrônica sobre o período medieval se revela bastante problemática, sobretudo quando a reflexão se desenvolve a partir das propostas da Nova História Política. Uma visão institucionalista, na qual o aparato normativo jurídico tem por objetivo submeter a sociedade à vontade monocrática do legislador (COELHO, 2016, p. 119), evidencia um problema anacrônico que, sem dúvidas, não auxilia a conhecer o período medieval. Ao apreender e refletir sobre a história filosófica do político, Pierre Rosanvallon, por exemplo, contribui para o entendimento de como os atores políticos enunciam as causas e direcionam as soluções, segundo o contexto em que se inserem (ROSAVALLON, 2010, p. 48). Reconstruir a maneira pela qual os atores entendem a sua situação, e compreendem seu próprio sistema político, ao invés de tentar medir a "eficácia política" com um olhar da nossa contemporaneidade, oferece aos historiadores novas perspectivas para a construção do objeto de estudo.

Tal proposta de análise histórica permite compreender como se configura o poder e como se comportam os agentes políticos nos tempos medievais. É de suma importância destacar que o ideal de poder, nesse período, não se coaduna com a ideia de um poder centralizado exercido de maneira monocrática, e sim com a existência de uma pluralidade de polos e jurisdições. O personalismo, característica desses polos de poder, é fundamental para o fortalecimento das instituições, ao dar prestígio às crescentes redes de poder, nas quais se apoia o sistema. O exercício do poder, segundo Maria Filomena Coelho, é sempre uma ação política que pressupõe necessariamente a interação com outros poderes, sem que nenhum deles possa deter o monopólio (COELHO, 2016, p. 122). A tendência historiográfica de colocar as monarquias medievais como polos de poder que se oporiam (ou deveriam se opor) à lógica feu- 


\section{O Poder na Idade Média}

Cássio Lopes Aquino

dal, como se fossem ensaios de "modernização" modo de análise que considera as instituições como forças que crescem como parte de um sistema singular. Dessa forma, cabe entender que o poder se define como parte das instituições, mas não deriva delas (COELHO, 2017, p. 19). A monarquia casteIhana, do século XV, se fortalece como parte de um sistema feudal, de forma orgânica, e não - como defende parte da historiografia - como força dicotômica frente à "anarquia medieval", que se estabelecia constantemente, sob a atuação de agentes "tipicamente" feudais que desejavam impedir o estabelecimento de um poder centralizado.

As obras de síntese sobre a história espanhola reverberam essa lógica institucionalista e, no que se refere a Álvaro de Luna, ele é mostrado como usurpador do caráter monocrático que o poder régio deveria apresentar ${ }^{4}$, agravada pela suposta debilidade régia de Juan II refletida na "anarquia" que dominou o seu governo. A rápida trajetória de ascensão de Álvaro de Luna teria incomodado vários grupos que já se encontravam estabelecidos na corte. Ao assumir gradativamente funções - como a de Gran Maestre de la Orden de Santiago e Condestable - que Ihe outorgavam poder militar e jurisdição sobre os membros da corte de Juan II, o valido ameaçou a posições e privilégios, incomodando não apenas os nobres de Castela (MANZANO MORENO, 2010, p. 634). Assim, explicita Eduardo Manzano Moreno:

Sinal evidente do caráter da monarquia castelhana é a presença no centro dessas contendas de validos régios, personagens nos quais os monarcas depositavam sua total confiança e que haviam assumido os recursos de poder, provocando com isso a rejeição de amplos setores da classe nobiliária. (MANZANO MORENO, 2010, p. 632. Tradução nossa).

\footnotetext{
3 Especialmente no século XV, em Castela, que é marcada pela unificação espanhola pelos Reis Católicos, em 1469.

${ }^{4} \mathrm{~A}$ interpretação e afirmação do suposto caráter usurpador de Álvaro de Luna é comum em boa parte da historiografia.
} 


\section{O Poder na Idade Média}

\section{Álvaro de Luna: A construção política da imagem do valido}

Contudo, ao assumir crescentes funções, atribuídas pelo rei, muitos dos contemporâneos passaram a enxergar esses acontecimentos como evidência de uma centralização do poder em torno do valido, usurpando o poder régio, o que gerou diversas acusações:

O primeiro deles, Álvaro de Luna, era apresentado por seus inimigos como um ambicioso bastardo da linhagem aragonesa dos Luna, que desde sua condição de pajem de Juan II havia chegado a controlar a vontade do monarca, o que conseguia graças a uma relação sobre a qual se lançavam acusações nada veladas "de algum trato indecoroso e de lascivas complacências", pois o rei não "queria que dormisse outro em sua câmara". Outros atribuíam o poder de Álvaro de Luna às "mágicas e diabólicas encantações para que [o rei] não pudesse fazer outra coisa, salvo o que ele quer". (MANZANO MORENO, 2010, p. 633. Tradução nossa).

Essas acusações sobre Álvaro de Luna acabaram por ser naturalizadas e incorporadas pela historiografia, como a principal imagem representativa do valido e de suas ações políticas. A consolidação do papel do valido como usurpador do poder régio, com base nas acusações de seus principais adversários políticos, passou a ser compreendido como um dos principais motivos das inúmeras disputas políticas que marcaram o governo de Juan II, principalmente frente aos infantes de Aragão. A caracterização de Julio Valdéon Baruque, em sua obra "El Reino de Castilla en la Edad Media", das ações do valido como "tirânicas" demonstra esse pensamento:

Se em ocasiões a oligarquia nobiliária castelhana pôde ver os infantes como seus líderes contra a tirania de dom Álvaro, também contribuiu fortemente para a eliminação dos infantes de Aragão da cena política castelhana (VALDÉON BARUQUE, 1968, p. 123. Tradução nossa). 


\section{O Poder na Idade Média}

Cássio Lopes Aquino

O autor também cita as vitórias militares e políticas do valido como forma de consolidar um "regime monárquico autoritário" e uma "ditadura pessoal", baseados no prestígio de Álvaro de Luna:

Parecia chegado o momento decisivo de subjugar a nobreza e consolidar o regime de autoritarismo monárquico baseado, claramente, no prestígio do favorito, dom Álvaro de Luna, o grande vitorioso da jornada. Mas, apesar das aparências, em Olmedo teve início a queda do condestável (1445-1453). Sua tentativa de estabelecer uma espécie de ditadura pessoal exasperou a oligarquia nobiliária (VALDÉON BARUQUE, 1968, p. 124-125. Tradução nossa).

Em outro exemplo de tal abordagem, Luís Suárez Fernández, em sua obra “Historia de España: Edad Media", classifica as ações políticas do valido como "absolutistas", além de caracterizá-lo como "usurpador":

Após grandes ações, destinadas a estimular a resistência contra o condestável, Afonso $V$ anunciou, como ultimato (4 de junho de 1425) que ia empreender a luta contra dom Álvaro, usurpador do governo. (...) Para acabar com dom Álvaro, o rei de Navarra precisava então do apoio da nobreza, descontente com o absolutismo do condestável (SUÁREZ FERNÁNDEZ, 1970, p. 507. Tradução nossa).

Eduardo Manzano Moreno, em sua obra "Historia de España", ao analisar a morte do valido, explica a necessidade de afastar Álvaro de Luna da corte para que a monarquia pudesse exercer sua função monocrática:

Apesar de seu triunfo, depois da batalha de Olmedo só restaram 8 anos de vida a Álvaro de Luna. A reafirmação do poder monárquico que ele tanto havia contribuído para reforçar acabou se voltando contra ele. Passada a euforia pela desaparição dos infantes da cena política castelhana e, sobretudo, pela partilha de suas extensas possessões entre os partidários do rei e do valido, começaram a ressurgir numerosas queixas contra a sua política. O poder do valido começou a declinar e, armado com seu "poderio real absoluto", Juan II se deu conta de que sua vontade poderia levar-Ihe a prescindir da pessoa cuja ascensão ele havia permitido (MANZANO MORENO, 2010, p. 637. Tradução nossa). 


\section{O Poder na Idade Média}

Álvaro de Luna: A construção política da imagem do valido

Ao defender que a decapitação do valido, pela a própria realeza, foi um episódio de reafirmação monárquica e de retomada do "poder real absoluto" por parte de Juan II, entende-se que Álvaro de Luna impedia constantemente a monarquia de se estabelecer como centro do poder. Portanto, o próprio poder régio deveria eliminá-lo. Em todas as abordagens dos autores aqui apresentados, o "privado" torna-se um exemplo daquilo que o período moderno concebeu para o conceito de valido, "os reis bons têm os ministros, os maus têm os validos" (BURKE, 1991, p. 106). Ou seja, os validos se reduzem a sujeitos cheios de ganância que tentavam manipular os reis através de suas vontades particularistas.

Porém, é importante entender que as fontes do período ${ }^{5}$ que retratam Álvaro de Luna representam um estado de opinião que é compartilhado por um grupo de interesses, e que a historiografia assumiu essas versões sem a reflexão crítica devida a uma literatura essencialmente política. Através de um estudo qualitativo dessas fontes, principalmente das crônicas, é interessante perceber as intenções e sentidos políticos que essas alcançam. O estudo das crônicas, que abordam a vida desse valido, possibilita conhecer as lógicas de representação sobre a política: a imagem construída de Álvaro de Luna decorre de um conteúdo político transformado em literatura, oriunda de um jogo intenso de poder durante o reinado de Juan II na Castela do século $\mathrm{XV}$. Ressaltar o cunho político da literatura do período, com uma intenção e sentido, é compreender a natureza apologética e propagandística que elas tinham em favor da-

\footnotetext{
${ }^{5}$ As crônicas do período do governo de Juan II são as principais fontes em relação aos acontecimentos da corte. Seu conteúdo é de suma importância para se compreender os eventos políticos que marcaram o seu governo. Elas também são as fontes mais citadas nos trabalhos historiográficos utilizados neste trabalho.
} 


\title{
O Poder na Idade Média
}

Cássio Lopes Aquino

quele que a encomendava (NIETO SORIA, 1998, p. 188-189). Trata-se, igualmente, de entender a concorrência de poderes dentro da própria corte de Juan II, da qual participava o próprio valido. Um jogo em aberto por meio do qual cada uma das partes classifica a outra como ilegítima (COELHO, 2017, p. 19).

As crônicas do reinado de Juan II configuram um instrumento de opinião política em favor de uma nobreza cortesã. Deste modo, deve-se refletir sobre o contexto que as envolve, e qual a importância de Álvaro de Luna para a própria monarquia, entendendo os atores políticos como produtos de seu tempo.

A caracterização de Álvaro de Luna como um usurpador do poder régio, imagem amplamente adotada pela a historiografia tradicional e que se estende ao próprio conceito de valimiento, pode ser encontrada em vários fragmentos da Crónica del Halconero de Juan II, de Pedro Carrilo de Huete. A súplica do rei de Navarra para Juan II afastar Álvaro de Luna de sua corte exemplifica tal aspecto:

\begin{abstract}
Muy excelente prínçipe Rey e señor: Porque de las cosas que por la presente dezir entendemos las más se aderençan al desordenado rregimiento de vuestros rreynos procurado por el vuestro condestable, desque vuestra señoría lo fizo e subió en el estado que es, usando entera e largamente de todo vuestro rreal poder, así avsoluto como ordinario, e posponiendo la onrra e preminençia que debidas eran a vuestra magestad rreal; e como los sabios antigos fablasen, dos maneras de prinçipar e señorear sobre gente, la vna natural, derecha e vuena, la otra tiránica e contraria, a vuestra señoría collegan que a outro más largamente conosçer qual de las dichas dos maneras el dicho condestable escogió e usó en el dicho rregimento, e cosas por él fechas, usurpando el dicho vuestro rreal poder, e querendo someter e sometiendo a sí todo quanto es, e fazerse monarca en vuestro rreynos (CARRILHO DE HUETE, 1946, p. 320).
\end{abstract}

O discurso aqui apresentado possui uma intenção política a favor dos inimigos de Álvaro de Luna. É interessante perceber como o rei de Navarra, nesse caso, faz questão de ensinar a Juan II como ele deveria se portar e de classificar a atuação do valido. A 


\section{O Poder na Idade Média}

\section{Álvaro de Luna: A construção política da imagem do valido}

necessidade de deslegitimar as ações de Álvaro de Luna diante do rei possui um sentido político evidente a favor de um grupo que combatia e se incomodava com o valido. A estratégia discursiva adotada pelo o rei de Navarra alega a "tirania" de Álvaro de Luna e, de forma indireta, a incapacidade de Juan II de ouvir as reclamações sobre o valido:

muy poderoso señor, rrazón non seria afirmar ni se fazer podría sin muy manifiesto herrar, el qual vuestro condestable, aliándose a de las dichas virtudes y buenas propriedades suso declaradas, pues todas carezen e sus obras son contra las virtudes dichas, con muy justa e legítima rrazón neçesario es mereçedor ser reputado e tenido conoçido tirano. E por tanto, muy excelente prínçipe, Rey y señor, vuestra rreal magestad deve abrir sus orejas para oyr todas las cosas que dichas son, con las siguientes, e otrosy los ojos de vuestro muy claro entendimiento para las sentir e entender, pues a Nuestro Señor plogo de vos conplir dél e de todas las sobredichas virtudes tan larga e enteramente que más ser non podría (CARRILLO DE HUETE, 1946, p. 323).

De fato, as acusações de que Álvaro de Luna era um "tirano", "usurpador", e afins, se encontram bastantes evidentes na fonte em questão. Contudo, a posição de quem adota esse discurso possui uma intenção política de invalidar o papel e as ações políticas do valido, por serem prejudiciais à própria monarquia castelhana. Porém, a Crónica de don Álvaro de Luna apresenta o outro lado do jogo político cortesão, adotando um discurso político favorável e enaltecedor às atitudes do valido. Destacam-se os principais sucessos políticos e militares daquele reinado, nos quais o condestable interveio com o seu valor e esforço (MIGUEL DE FLORES, 1784, p. 3):

Fué muy inventivo é mucho dado á falar inenviones, é sacar entremeses en fiestas, ó en justas, ó en guerra: en las quales invenciones muy agudamente significaba lo que queria. Fué muy nombrado cavalgador en ambas sillas, é grand bracero: é dió grand cuidado de tener Buenos caballos é ligeros: deleytabase mucho en facer corregir sus armas é requerirlas, é tenerlas netas é limpias, é á punto. Fué en la guerra demasiadamente esforzado é atrevido, tanto, que se metia muchas veces en logares de grand peligro, segund en esta su historia, é 


\section{O Poder na Idade Média}

Cássio Lopes Aquino

en otras muchas partes paresce. Comportaba mucho las armas, é afanabase mucho en la guerra. Fablaba en todos tiempos con grand reverencia é cirimonia á su Rey (MIGUEL DE FLORES, 1784, p. 182-183).

Evidentemente, o discurso adotado por essa crônica tem o objetivo de produzir um testemunho para perpetuar a boa fama de Álvaro de Luna e os seus valores cavaleirescos. Ela se apresenta como um relato particular, centrado na pessoa do condestable, promovendo um discurso político paralelo ao objeto de descrição da crônica régia (GALLARDO, 2006, p. 429). Ao contrário da Crónica del Halconero, sua intenção é promover um manifesto político favorável a personagem, apresentando uma imagem oposta à das acusações que os seus inimigos lhe atribuíam. O capítulo que narra a morte de Álvaro de Luna exemplifica essa estratégia discursiva: "Titulo CCXXVIII. De la muerte del mejor caballero que en todas las Españas ovo en su tiempo, é mayor señor sin corona, el buen Maestre de Santiago." (MIGUEL DE FLORES, 1784, p. 376).

É importante destacar como a estratégia narrativa adotada pelas crônicas abordadas são antagônicas mesmo em se tratando do mesmo personagem. Tal diferença deriva dos diferentes locais de produção dessas narrativas. A composição, de cunho negativo, por parte da Crónica del Halconero, deriva do pensamento da corte régia sobre Álvaro de Luna, local de produção dessa fonte. De fato, a importância política que o valido atingiu não era bem quista, o que provocava bastante desconfiança e recriminação por parte de integrantes da corte. Isso causava discursos de deslegitimação contra o "privado". A Crónica de don Álvaro de Luna foi produzida no ambiente senhorial do próprio valido. Para François Foronda, o apoio à posição do privado na corte era a nobreza média, que representou a principal base social das redes clientelares construídas por Álvaro de Luna, a partir de sua ascensão (FORONDA, 2010, p. 431). Ademais, sua proximidade ao rei permitiu-lhe acumular e ampliar bens e territó- 


\section{O Poder na Idade Média}

Álvaro de Luna: A construção política da imagem do valido

rios, expandir sua rede e engrandecer sua linhagem (FORONDA, 2010, p. 434). Portanto, a crônica de Álvaro de Luna representava, igualmente, uma exaltação do senhor que ele foi, o qual possuía amplas redes de vassalagem, em um contexto feudal, que auxiliaram no seu crescimento político dentro da corte régia. Ou seja, a imagem de Álvaro de Luna dependeria da autoria do discurso e de se considerar a tipologia da narrativa.

Contudo, a imagem a posteriori de Álvaro de Luna foi fruto da versão que os vencedores difundiram. O papel político do valido acabou por ser classificado como "usurpador" do poder régio, devido às sucessivas derrotas que ele sofreu, após vencer os Infantes de Aragão, em 1448, seguidas por mudanças substanciais na corte de Juan II, como o casamento do rei com Isabel, de Portugal. Isto acabou por provocar o crescimento do discurso político contrário ao seu poder, que acusava Juan II de incapacidade de comandar o seu próprio reino. Nesse sentido, observa-se, que a historiografia incorporou o discurso dos vitoriosos, acrescido de opiniões negativas que consideram que os validos impediam o exercício do poder monocrático do rei.

Frequentemente se esquece, nas análises historiográficas, que a ampla rede clientelar de Álvaro de Luna dava prestígio à própria monarquia castelhana, uma vez que a personagem representava o poder régio. O valido exerce o poder, por meio de lógicas de tipo pluralistas que se conjugam e se retroalimentam: da cabeça aos membros superiores e vice-versa (COELHO, 2017, p. 12). Antepor o poder do valido ao do rei não faz sentido naquele contexto, a menos que se tome apenas um dos lados desse cenário. As intrigas políticas provocadas pelos integrantes da corte eram chefiadas por indivíduos que possuíam capacidade de influência política na administração do reino. As constantes acusações a Álvaro de Luna não possuíam o intuito de defender 


\title{
O Poder na Idade Média
}

Cássio Lopes Aquino

a força monopolizadora e centralizadora que o monarca deveria apresentar, mas de defender os espaços que estavam sendo ocupados por forças concorrentes. O fenômeno do valimiento no governo de Juan II parece ter sido essencial para o fortalecimento e prestígio da monarquia, pelo próprio espaço da corte ser reconhecido como um lugar de excelência de poder (ALMEIDA, 2018, p. 179-180).

A dimensão das redes que Álvaro de Luna possuía e sua capacidade de influência pode ser percebida na capela da catedral de Toledo, em que seu corpo foi enterrado. Apesar de ter sido humilhado e executado pelo tribunal régio, a Capela de Santiago, construída a mando do próprio "privado" para ser seu local de enterramento (ROCHA, 2015, p. 145), demonstra a magnitude do poder que o valido possuía na principal cidade do reino, onde se concentrava a maior parte de suas redes de poder. A capela possui a intenção política de engrandecer a imagem do condestable, assim como de fazer perdurar a sua linhagem e criar uma memória visual. Estas finalidades auxiliam a entender a dimensão política que Álvaro de Luna representava no seio da monarquia castelhana, a qual não se extingue com a sua condenação e morte, pois mesmo após esse dramático desfecho, executado como inimigo da coroa, foi sepultado em uma das maiores capelas da catedral de Toledo:

\begin{abstract}
Allende desto el noble é magnifico Maestre por tener grand parte de sus señorios comarcanos á la muy noble cibdad de Toledo, é aver edificado en la Santa Iglesia della la mas notable, rica é maravillosa capilla é enterramiento suyo, que en las Españas, é aún en la mayor parte del mundo se pudiesse fallar, que paresció tener en la cibdad grand parte de su assiento; todos los nobles caballeros della eran en su casa, é avian dél dineros (MIGUEL DE FLORES, 1784, p. 390).
\end{abstract}

Portanto, Álvaro de Luna está perfeitamente integrado nos espaços de poder político e alimenta, com o prestígio que Ihe advém da coroa, uma ampla rede de be- 


\section{O Poder na Idade Média}

\section{Álvaro de Luna: A construção política da imagem do valido}

neficiados que, por sua vez, são testemunhas e engrandecem o prestígio do reino de Castela. Ele não é visto, na qualidade de Condestável e de Grão-mestre de Santiago, como força opositora da monarquia, e sim, como parte de um corpo político que dava prestígio à monarquia, e vice-versa. A intenção de Juan II em manter Álvaro de Luna na corte e de agraciá-lo com diversos cargos políticos importantes pode ser entendida como forma da monarquia aumentar sua fama ao atrair para a sua esfera de influência um importante polo de poder. A cultura política de tipo pluralista, em que vários polos compartilham o poder, pressupõe a colaboração mútua, em que os envolvidos acreditam atuar para o bem-comum. A monarquia castelhana se fortalece como parte de um sistema e a figura de Álvaro de Luna se coloca como um dos variados polos de poder que elevam a figura régia, a partir do próprio poderio clientelar que o valido construiu durante sua permanência na corte. Pode-se compreender a monarquia castelhana e Álvaro de Luna como produtos de seu tempo e de uma lógica de tipo pluralista que os fortaleciam como parte de um sistema feudal, e não como forças opostas por natureza.

\section{O problema da historiografia nacional e sua abordagem do século XV cas- telhano}

As grandes narrativas de síntese da História da Espanha costumam considerar os acontecimentos políticos do século XV, como essenciais para a consolidação de uma unidade nacional, operada pelos Reis Católicos, Isabel de Castela e Fernando de Aragão. Tal perspectiva acaba por influenciar a maneira como se interpretam os reinados que antecederam esse momento de "apogeu": o de Juan II e o de Enrique IV. Assim, o transcurso do século XV é caracterizado como um período "anárquico" que 


\title{
O Poder na Idade Média
}

Cássio Lopes Aquino

conduziu a Espanha à necessidade de centralizar o poder por meio de uma monarquia autoritária, que guiaria o território espanhol à modernidade:

\begin{abstract}
A tensão, ao menos superficialmente, aumenta no século XV, com Juan II e Enrique IV. Mesmo assim, a solução final será o estabelecimento de uma monarquia autoritária, a dos Reis Católicos. Isso indica que a anarquia do século XV castelhano refletia mais uma crise de crescimento que uma autêntica decadência. (...) O século longo, que se estende desde meados do século XIV até a morte do débil monarca Enrique IV (1474), é, se observado de uma determinada perspectiva, a época do acaso da monarquia medieval castelhana. Mas se Castela parece declinar é, na verdade, para dar espaço a uma nova etapa, mais fecunda, a de unidade nacional, conseguida sob sua direção, prova inequívoca de que a debilidade era mais aparente do que real (VALDÉON BARUQUE, 1968, p. 105 e 107. Tradução nossa).
\end{abstract}

A maneira de entender os acontecimentos do século XV como antecedentes necessários para a unidade nacional é bastante problemática. A interpretação historiográfica lança mão de uma interpretação teleológica pela qual o passado estava inexoravelmente condicionado para conduzir a nação até uma determinada configuração política (CARVALHO, 2015, p. 49). Essa forma de explicar o passado possui a intenção de apresentar a história do estabelecimento e sucesso da nação por meio da centralização do poder e da eliminação de forças políticas concorrentes à monarquia. Ao mesmo tempo, a criação de uma identidade nacional apoia-se igualmente em uma narrativa da existência da nação através dos tempos, bem como da sua singularidade, que, por sua vez, é construída por meio de um constante processo de diferenciação com relação ao "outro" (CARVALHO, 2015, p. 84).

A necessidade de consolidar um caminho positivo na construção da memória de uma nação exige encontrar agentes, definidos como próprios de seu tempo, que impediam tal realização. Em vista disto, os governos de Juan II e de Enrique IV são definidos pela a historiografia como ineficazes, por serem dirigidos por reis "fracos e débeis" que não foram capazes de controlar sua própria corte e as disputas políticas em seus reinados. De tal maneira, os validos dos dois governos, por protagonizarem 


\section{O Poder na Idade Média}

Álvaro de Luna: A construção política da imagem do valido

diversas disputas políticas, acabam por ser identificados como usurpadores e agentes impedidores da centralização monárquica que deveria guiar à modernidade. A estruturação de uma memória nacional, identificada com o Estado, precisa encontrar personagens antagonistas à autoridade que ressaltem, pela negativa, as vantagens da concentração de poderes em torno da monarquia e a unidade nacional.

A imagem de Álvaro de Luna é influenciada por esta construção nacional, alimentada pelas diversas acusações que sofreu, registradas nas fontes documentais produzidas por seus inimigos e incorporadas em boa medida pelos historiadores. $O$ condestable é colocado na vasta galeria daqueles personagens do século XV que eram "incapazes" de compreender o projeto de fabricação da nação. Essa perspectiva limita a compreensão sobre a complexidade dos episódios que marcaram e definiram os rumos políticos castelhanos, assim como impede entender o exercício do poder na monarquia medieval. O discurso de deslegitimação dos reinados que antecederam os Reis Católicos torna-se um instrumento para um projeto político de afirmação da unidade nacional que, supostamente, foi por eles fundada. Encontrar personagens que guiaram a nação para a prosperidade e modernidade envolve, igualmente, construir uma narrativa que culpe personagens anteriores por terem impedido a realização do que se considera uma espécie de natureza política: a nação. Com isto, a caracterização dos governos castelhanos do século XV, como "anárquicos", comandados por reis "fracos" facilmente influenciados por seus validos "usurpadores", se torna uma narrativa de fácil aceitação para os sentimentos nacionais espanhóis, refletidos nas figuras simbólicas dos Reis Católicos.

\section{Reflexões finais}




\section{O Poder na Idade Média}

Cássio Lopes Aquino

Ao confrontarmos o cenário político que envolve Álvaro de Luna com a bibliografia que se debruça sobre a sua atuação política, observa-se como as lógicas estatistas anacrônicas são recuadas até o período medieval. O próprio conceito de valido, entendido como perturbador da ordem política, e as associações que se estabelecem com o termo "privado", revela o anacronismo que está na base de boa parte das análises historiográficas. Entender o século XV, em Castela, e os agentes políticos como frutos de uma cultura política própria, assentada em lógicas políticas de tipo pluralista, parece ser de vital importância para se compreender os acontecimentos da época.

A imagem de Álvaro de Luna nas fontes é evidentemente um constructo político próprio do embate entre os grupos de interesses que ocupavam a corte no reinado de Juan II. A análise naturalizada do conteúdo das crônicas acabou por converter o valido em uma figura negativa que não permite entender as dinâmicas de poder que o envolviam e pelas quais ele alcançava um prestígio político identificado com o próprio reinado. Dessa forma, a imagem que as crônicas apresentam do valido deve ser interpretada com uma profunda análise crítica do seu conteúdo, a partir da sua tipologia documental e do contexto que as produziu. A monarquia castelhana se fortalece pelas redes clientelares do privado, e a constante atribuição de ofícios régios ao valido é uma forma de exercer o poder, que considera necessário fortalecer diversos núcleos de poder que, embora ajam de maneira concorrente, contribuem para solidificar um modelo político cristão, em que as particularidades somente se realizam dentro da unidade do corpo. Uma concepção pluralista de poder, onde um membro - mesmo que seja o rei - não pode eclipsar os demais.

Portanto, refletir sobre a maneira como a historiografia explica os reinados castelhanos do século XV que antecederam os Reis Católicos - exemplos de instabilidade que justificariam a necessidade de instaurar uma monarquia autoritária - conecta-se 


\section{O Poder na Idade Média}

Álvaro de Luna: A construção política da imagem do valido

diretamente com o viés com que se costuma analisar a trajetória de Álvaro de Luna. A evidente associação entre Estado e monarquia reduz muito o cenário político e a legitimidade dos atores que, tal como Ávaro de Luna, com suas redes particulares, contribuíam de forma positiva para o fortalecimento do poder régio no século XV. Mas obviamente tal percepção exige que o historiador deixe de considerar como ponto de comparação, um determinado modelo de nação e de Estado.

De fato, entender como as instâncias de poder na Idade Média pertencem a matrizes pluralistas de poder, exige alargar o arcabouço de referências políticas. A existência de diversos polos de poder envolvia tanto instituições, reconhecidas como autoridades legítimas, assim como redes clientelares. A forma de associação entre esses polos é sempre regida pela busca do bem-comum e a harmonia entre os corpos $^{6}$, onde um não pode impedir o outro de exercer seu poder. Tal maneira de pensar a própria imagem do valido Álvaro de Luna, por suas amplas redes de influência, pode ajudar nos estudos acadêmicos que envolvem o conceito de valido, a sua biografia e a própria história castelhana. As instituições e os personagens são moldados por uma dinâmica que acaba por dar forma a suas ações e pensamentos refletindose, posteriormente, nos registros da memória por parte dos vencedores da luta política, que são assumidas de maneira naturalizada pela historiografia, como verdades históricas. Portanto, Álvaro de Luna e a monarquia castelhana devem ser entendidos como produtos do seu próprio tempo, onde ambos agiam organicamente, de forma conjunta e plural, fortalecendo-se como parte de um sistema e de experiências políticas

$$
\text { próprias }
$$

do

período

medieval.

\footnotetext{
${ }^{6}$ Esclarecendo que, na concepção do modelo corporativo, harmonia não significa ausência de conflito ou de guerra. Ver: COELHO, 2019, p. 7-8.
} 


\section{O Poder na Idade Média}

Cássio Lopes Aquino

\section{Fontes}

CARRILLO DE HUETE, Pedro. Crónica del Halconero de Juan II. MATA CARRIAZO, Juan de; BELTRÁN, Rafael (eds.). Granada: Universidad de Granada, 2006.

MIGUEL DE FLORES, Josef. Crónica de D. Álvaro de Luna, condestable de los reynos de Castilla y de Leon. Copia digital. Valladolid: Junta de Castilla y Léon. Consejería de Cultura y Turismo, 2009-2010. En Madrid: en la imprenta de D. Antonio de Sancha, 1784.

PÉREZ DE GUZMÁN, Fernán. Crónica del señor don Juan, segundo de este nombre em Castilla y en Leon. Copia digital. Valladolid: Junta de Castilla y León. Consejería de Cultura y Turismo, 2009-2010. En Valencia: en la imprenta de Benito Monfort, 1779.

\section{Referências bibliográficas}

ALMEIDA, Scarlett Dantas de Sá. O papel do privado no reinado de Juan II de Castela: traço de uma monarquia fraca? COELHO, M. F.; PESSOA, F.; CANABRAVA, J. V. (eds.) Os manuscritos medievais da UnB. Atas das sessões das comunicações da IX Semana de Estudos Medievais. Brasília: PEM-UnB, 2018, p. 174-180

BURKE, Peter. O Cortesão. In: GARIN, Eugenio (org.). O homem renascentista, Lisboa: Presença, 1991.

CARCELLER CERVIÑO, María del Pilar. Álvaro de Luna, Juan Pacheco y Beltrán de la Cueva: un estudio comparativo del privado regio a fines de la Edad Media. In: España Medieval, $n^{\circ} 32,2009$, p. 85-112.

CARVALHO, Luís Fernando de. 0 recrudescimento do nacionalismo catalão: estudo de caso sobre o lugar da nação no século XXI. Brasília: FUNAG, 2015.

COELHO, Maria Filomena. A jurisdição da aristocracia cristã: monarquia, nobreza e monacato em Portugal. In: Locus: revista de história, Juiz de Fora, v. 22, n. 1, 2016.

- Um universo plural: política e poderes públicos na Idade Média (séc. XII XIII). In: La Edad Media en perspectiva latino-americana. San José: Ed. de la Universidad Nacional de Costa Rica, 2017.

. Interpretações de António Hespanha: "alguns enviesamentos correntes", recorrentes e renitentes. Disponível em: 


\section{O Poder na Idade Média}

Álvaro de Luna: A construção política da imagem do valido

https://www.academia.edu/41886505/Interpreta\%C3\%A7\%C3\%B5es de Ant\%C3\%B3n io Hespanha alguns enviesamentos correntes recorrentes e renitentes. Acesso em: 10 abr 2020.

FORONDA, François. La privanza, entre monarquía y nobleza. In: NIETO SORIA, José Manuel (org.). La monarquía como conflicto en la corona castellano-leonesa (C. 1230-1504). Madrid: Sílex ediciones, 2006, p. 73-132.

Patronazgo, relación de clientela y estrutura clientelar. El testimonio del Epílogo de la Historia de don Álvaro de Luna. In: Hispania. Revista Española de Historia, vol. LXX, núm. 235, mayo-agosto, 2010.

GALLARDO, Luis Fernández. La biografía como memoria estamental. In: NIETO SORIA, José Manuel (org.). La monarquía como conflicto en la corona castellano-leonesa (C. 1230-1504). Madrid: Sílex ediciones, 2006, p. 423-488.

MANZANO MORENO, Eduardo. Épocas medievales. In: FONTANA, J.; VILLARES, R.. Historia de España. Madrid: Critica/Marcial Pons, 2010.

NIETO SORIA, José Manuel. Apología y propaganda de la realeza en los cancioneiros castellanos del siglo XV. Diseño literário de un modelo político. In: En la España medieval, Madrid, $n^{\circ} 11,1998$.

ROCHA, Cinthia. Álvaro de Luna e os discursos políticos da Capela de Santiago. In: SALVADOR GONZÁLEZ, José María (org.). Mirabilia Ars 2, Barcelona, 2015.

ROSANVALLON, Pierre. Por uma história filosófica do político. In: Por uma história do político. São Paulo: Alameda Casa Editorial, 2010.

SUÁREZ FERNÁNDEZ, Luis. Historia de España: Edad Media. Madrid: Editorial Gredos, S.A., 1970.

TOMÁS Y VALIENTE, Francisco. Los validos en la monarquía española del siglo XVII. Madrid: Siglo XXI de España Editores, 1982.

VALDEON BARUQUE, Julio. Reino de Castilla en la Edad Media. In: SUÁREZ FERNÁNDEZ, Luis (org.). Panoramas de la historia universal. Bilbao: Ediciones Moreton, S.A., 1968. 